\title{
Interactions of Corticotropin-Releasing Factor, Urocortin and Citalopram in a Primate Model of Stress-Induced Amenorrhea
}

\author{
Karin V. Weissheimer ${ }^{a}$ e $\quad$ Skyla M. Herod ${ }^{a} \quad$ Judy L. Cameron ${ }^{d}$ \\ Cynthia L. Bethea ${ }^{\mathrm{a}-\mathrm{c}}$
}

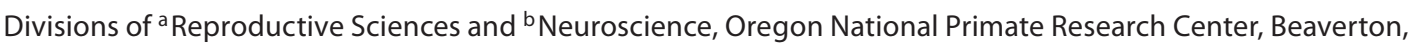
Oreg., 'Department of Behavioral Neuroscience, Oregon Health and Science University, Portland, Oreg., and ${ }^{\mathrm{d}}$ Department of Psychiatry, University of Pittsburgh, Pittsburgh, Pa., USA; ${ }^{\circ}$ Department of Physiology, Institute of Basic Health Sciences, Federal University of Rio Grande do Sul, Porto Alegre, Brazil

\section{Key Words}

Stress $\cdot$ Selective serotonin reuptake inhibitor $\cdot$

Corticotropin-releasing factor - Urocortin I - Dorsal raphe •

Serotonin - Macaques

\begin{abstract}
Background/Aims: We established a cynomolgus macaque model of stress-induced amenorrhea in which the application of combined metabolic and psychosocial stress suppressed ovulation in stress-sensitive (SS) individuals, but not in highly stress-resilient (HSR) individuals. We previously reported that SS monkeys have deficits in global serotonin release and serotonin-related gene expression in the raphe nucleus, and that administration of the selective serotonin reuptake inhibitor S-citalopram increased estrogen and progesterone production in SS monkeys. In this study, we questioned whether there was a difference in corticotropin-releasing factor (CRF) or urocortin (UCN) stress-related peptide systems in the midbrain raphe region when HSR and SS monkeys treated with placebo or S-citalopram are compared. Methods: Monkeys characterized as HSR or SS were administered placebo or S-citalopram for 15 weeks. CRF fibers in the dorsal raphe were detected with an antibody against human CRF. UCN1 fibers were immunostained in an area rostral
\end{abstract}

to the dorsal raphe. The fibers were quantified by stereology and analyzed by two-way ANOVA. UCN1 cell bodies were counted in the supraoculomotor area near the EdingerWestphal nucleus. Results: S-citalopram significantly decreased the CRF fiber density in SS animals, but not in HSR animals. SS monkeys had a significantly lower UCN1 fiber density compared to HSR monkeys, but S-citalopram treatment did not alter the UCN1 fiber density. SS animals treated with S-citalopram tended to have a higher number of UCN1positive cell bodies than the other groups. Conclusion: Scitalopram decreased CRF fiber density and appears to increase the production of UCN1 in SS individuals, indicating the likelihood that serotonin is involved in regulating CRF and UCN1 in individuals who are sensitive to the effects of serotonin.

Copyright $\odot 2010$ S. Karger AG, Basel

\section{Introduction}

International estimates indicate a $9 \%$ prevalence of infertility (of 12 months) [1], and approximately 30\% of women presenting at infertility clinics in the USA are diagnosed with functional hypothalamic amenorrhea, which has lately been called 'stress-induced amenorrhea'

\section{KARGER}

(C) 2010 S. Karger AG, Basel

Fax +4161306 1234

E-Mail karger@karger.ch

www.karger.com
Accessible online at:

www.karger.com/nen
Dr. C.L. Bethea

Oregon National Primate Research Center

OHSU West Campus, 505 NW 185th Ave

Beaverton, OR 97006 (USA)

Tel. +1 503690 5327, Fax +1 503690 5384, E-Mail betheac@ohsu.edu 
[2-4]. We have developed an experimental nonhuman primate model of hypothalamic amenorrhea in which mild psychosocial stress combined with a mild metabolic stress, such as diet or a moderate exercise regimen, leads to a suppression of the reproductive function which is reversed upon stress removal [5-7]. Results from studies of this model have important implications for thousands of infertile women. Using this monkey model, we found that some individuals are sensitive to stress-induced suppression of reproductive function, while others are stress resilient. Female cynomolgus monkeys are either (1) highly stress resilient (HSR) and maintain normal menstrual cycles when exposed to 2 cycles of combined stress, or (2) medium stress resilient (MSR) and are ovulatory in the first menstrual cycle involving stress exposure, but anovulatory in the second stress cycle, or (3) stress sensitive (SS) and become anovulatory as soon as stress is initiated $[5,6,8]$.

We have shown that even in nonstressed conditions there are differences in the function of several key neural systems in SS versus SR monkeys. SS animals chronically have a lower release of serotonin $(5-\mathrm{HT})$ in response to fenfluramine [6], and have a downregulation of the central serotonergic system, as indicated by significantly less tryptophan hydroxylase 2 (TPH2) expression [9], less serotonin reuptake transporter (SERT) gene expression, less $5-\mathrm{HT}_{1 \mathrm{~A}}$ receptor gene expression and less expression of the genes that degrade serotonin (MAO-A and MAO$B)$ in the raphe nucleus $[7,10]$. In the hypothalamus, there is an upregulation of $5-\mathrm{HT}_{2 \mathrm{~A}}$ and $5-\mathrm{HT}_{2 \mathrm{C}}$ receptors [11], and an increase in GAD67 gene expression [11], which are inhibitory to the reproductive axis. We also found that SS animals have less immunoreactive gonadotropin-releasing hormone $(\mathrm{GnRH})$ in the median eminence, lower pituitary luteinizing hormone and follicle-stimulating hormone secretion, and lower ovarian estradiol and progesterone secretion compared to more stress-resilient monkeys, even when they are not experiencing stress $[10,12]$.

We also found a significant increase in corticotropinreleasing factor (CRF) gene and protein expression in the hypothalamic paraventricular nucleus (PVN) of SS individuals compared to HSR individuals [13]. In many stressful situations, the hypothalamic-pituitary-adrenal axis becomes activated with increases in CRF, adrenocorticotropic hormone and cortisol, and CRF may inhibit GnRH release [14-16]. In clinical studies, individuals with depression or anxiety or with suicidal tendency exhibited more CRF neurons in the hypothalamus than normal individuals $[17,18]$. Moreover, CRF neurons and fibers are found in numerous limbic structures outside of the hypothalamus, including the dorsal raphe nucleus, and they mediate stress responses [19-21].

Another peptide system involved in the regulation of stress and anxiety is the urocortin (UCN) system, which bears some homology with CRF [22]. Three UCN peptides have been characterized: UCN1, UCN2 and UCN3; both CRF and UCN1 fibers innervate the primate dorsal raphe nucleus $[23,24]$. UCN1 is involved in the stress adaptation response [25] and in stress-induced anxiety [26]. Moreover, UCN1 neurons respond to alcohol and may affect alcohol preference and consumption [27]. Evidence from rodents suggests that, once released into the raphe, CRF and UCN1 bind to CRF receptor 1 (CRF-R1) and CRF receptor 2 (CRF-R2) and regulate serotonin neurotransmission [28-31].

Recently, we characterized a new population of monkeys as SS and HSR, and then treated them with the antidepressant escitalopram or placebo for 15 weeks in the absence of stress [32]. We found that there was an increase in peak estradiol and progesterone secretion only in the SS group treated with escitalopram, suggesting that central neural drive to the reproductive axis was improved by escitalopram treatment [32].

Escitalopram is an antidepressant drug used to treat major depressive disorder, generalized anxiety disorder, social anxiety disorder or panic disorder. Escitalopram belongs to a class of drugs known as selective serotonin reuptake inhibitors (SSRI); it is the S-stereoisomer (enantiomer) of the earlier drug, citalopram, and it has the highest affinity for the transporter of any of the SSRI. Thus, how this mechanism of action transmitted to an increase in ovarian steroid secretion became of interest.

The pharmacological actions of S-citalopram indicate that the serotonin system was a primary cite of action. Therefore, we examined the expression of 4 pivotal genes that regulate the function of the serotonin neural system. We found that the expression of the master serotonin developmental gene Fev (Fifth Ewing variant), as well as that of TPH2, SERT and $5-\mathrm{HT}_{1 \mathrm{~A}}$ mRNA was significantly compromised in SS animals, but that escitalopram treatment for 15 weeks did not alter the expression of these genes [9]. This suggested that the effect of S-citalopram on reproductive function was mediated by a mechanism other than gene expression in serotonin neurons. Because we had observed higher CRF gene and protein expression in the PVN of SS animals, we questioned whether there was a difference in the CRF and UCN1 stress-related peptide projection systems in the midbrain raphe region, and whether S-citalopram altered these parameters. 


\section{Materials and Methods}

\section{Animals and Treatments}

All studies were reviewed and approved by the Institutional Animal Care and Use Committee of the Oregon National Primate Research Center and performed according to federal guidelines. Twenty-five female cynomolgus monkeys started the study, but 16 were utilized for neuroanatomical assays in a $2 \times 2$ block design with 4 animals per group as explained below. They were housed in single cages, in large rooms with other monkeys. Movement of monkeys within the room, and in and out of the room, was limited so that the monkeys had a stable social environment for 4 months. The monkeys were fed commercially available monkey chow (12 pellets of Purina High Protein monkey chow) once a day at about $11.00 \mathrm{~h}$ supplemented with fruit. Water was available ad libitum.

Menstrual cycles were monitored by daily swabbing of the vaginal area with a cotton-tipped applicator. The monkeys were trained in the routine of jumping from their home cage into a portable carrying box for transport to a restraint cage, and then extending their leg for blood sample collection by femoral venipuncture. They appeared to readily adapt to the procedure, as evidenced by normal cortisol levels. Blood samples were collected every other day by femoral venipuncture to monitor reproductive hormones throughout the study. To categorize the monkeys as HSR or SS, they were moved to a new housing room, surrounded by unfamiliar monkeys and put on a diet change eating $80 \%$ of the food they consumed during the control phase of the study. Their menstrual cyclicity and reproductive hormones were evaluated for 2 months after the move/diet, as previously described [7]. Based upon the menstrual response to this combined psychosocial and metabolic stress, the monkeys were labeled HSR $(n=8)$, MSR $(n=4)$, SS $(n=7)$ and very SS (VSS; $n=6)$. The VSS animals did not exhibit cycles for 4 months of observation in their home cage, and so they were not moved.

At the end of the 4-month period ( 1 month of control, 1 month of learning to run, 2 months of stress), all of the animals in the paradigm were returned to their home cage and allowed to eat ad libitum. Approximately half of each group was treated with vehicle (placebo, $\mathrm{Pb}$ ) and the other half was treated for 15 weeks with $1.2-4.8 \mathrm{mg} / \mathrm{kg}$ of S-citalopram (b.i.d.) to elevate blood concentrations of S-citalopram to the therapeutic range for treating depression. Blood samples were collected twice from representative animals to monitor blood citalopram levels by chiral reversed-phase liquid chromatography $[33,34]$, and doses were adjusted if necessary to keep the levels in the target range of $20-40 \mathrm{ng} / \mathrm{ml}$, as observed in depressed patients. After about 1-2 weeks, blood levels of S-citalopram at 3 and $6 \mathrm{~h}$ after dosing averaged $24.8 \pm 5.0$ and $13.5 \pm 3.6 \mathrm{ng} / \mathrm{ml}$, respectively, and the significantly less active metabolite, desmethyl-S-citalopram averaged $12.1 \pm 1.7$ and 8.7 $\pm 1.8 \mathrm{ng} / \mathrm{ml}$, respectively ( $\mathrm{n}=5$ animals), which required adjustment. After a further 3 weeks, blood levels of S-citalopram at 3 and $6 \mathrm{~h}$ after dosing averaged $23.7 \pm 6.2$ and $22.4 \pm 5.7 \mathrm{ng} / \mathrm{ml}$, respectively, and desmethyl-S-citalopram averaged $13.0 \pm 3.1$ and $13.0 \pm 3.1 \mathrm{ng} / \mathrm{ml}$, respectively ( $\mathrm{n}=6$ animals). Menstrual cyclicity and reproductive hormones were monitored throughout the S-citalopram treatment as described above.

The S-citalopram treatment was physiologically efficacious, as indicated by an improvement in ovarian steroid secretion [32]. The groups that showed some sensitivity to stress (MSR, SS and
VSS groups) were combined $(\mathrm{n}=17)$ and compared to the HSR group $(\mathrm{n}=8)$. In SS monkeys, S-citalopram treatment significantly increased peak estradiol levels in the follicular phase of the menstrual cycle from $360 \pm 67$ to $544 \pm 82 \mathrm{pg} / \mathrm{ml}(\mathrm{p}<0.05)$, and increased peak progesterone levels in the luteal phase of the menstrual cycle from $6.7 \pm 1.4$ to $11.3 \pm 1.8 \mathrm{ng} / \mathrm{ml}(\mathrm{p}<0.05)$. In contrast, $\mathrm{Pb}$ - and $\mathrm{S}$-citalopram-treated HSR monkeys had similar peak estradiol and peak progesterone before and after treatment, which averaged (both groups) $575 \pm 100 \mathrm{pg} / \mathrm{ml}$ and $11.5 \pm 3 \mathrm{ng} /$ $\mathrm{ml}$, respectively. For the subsequent neuroanatomical analysis, only the SS and VSS groups were combined. The MSR animals were not included, as explained below.

\section{Tissue Preparation}

The monkeys were euthanized according to the procedures recommended by the Panel on Euthanasia of the American Veterinary Association. Each animal was sedated with ketamine, given an overdose of pentobarbital ( $25 \mathrm{mg} / \mathrm{kg}$, i.v.) and exsanguinated by severance of the descending aorta.

The left ventricle of the heart was cannulated and the head perfused with 1 liter of saline (made with diethylpyrocarbonatetreated water, $0.1 \%$ diethylpyrocarbonate, to minimize RNase contamination) followed by 7 liters of $4 \%$ formaldehyde in $3.8 \%$ borate, $\mathrm{pH} 9.5[35,36]$. The brain was removed and the pontine midbrain dissected from the rostral to the caudal borders of the pons. The pontine midbrain block displayed the rounded central canal on its anterior surface and the wing-shaped canal on its caudal surface. Blocks of tissue containing the pontine midbrain were postfixed for $3 \mathrm{~h}$ in $4 \%$ formaldehyde, then washed in $0.02 \mathrm{M}$ potassium phosphate-buffered saline (KPBS) containing first $10 \%$ (overnight), then $20 \%$ glycerol ( $48 \mathrm{~h}$ ), plus $2 \%$ DMSO to cryoprotect the tissue. The blocks were frozen in precooled methylbutane $\left(-55^{\circ} \mathrm{C}\right)$ and stored at $-80^{\circ} \mathrm{C}$ for up to 6 months.

\section{Post hoc Animal Selection for Tissue Analysis}

The 8 HSR animals that were treated with $\mathrm{Pb}$ or S-citalopram were all included ( $\mathrm{n}=4$ per treatment). The 4 animals that were MSR yielded only 2 each for $\mathrm{Pb}$ or S-citalopram treatment, so they were excluded due to insufficient numbers for statistical analysis. The SS and VSS groups were grouped together as stress sensitive. Five SS animals were treated with $\mathrm{Pb}$, but 1 animal had a poor perfusion of the brain, so the remaining 4 animals were included. Eight SS animals were treated with S-citalopram. In order to match the other 3 groups, 4 of the 8 animals, which never cycled or which exhibited immediate cessation of ovulation upon moving, were included in the tissue analysis providing 4 per group in a $2 \times 2$ block design. The midbrain blocks containing the Edinger-Westphal nucleus and the dorsal raphe were cut on a sliding microtome at $25 \mu \mathrm{m}$. Floating sections from the midbrain block were stored in cryoprotectant solution (50\% $0.05 \mathrm{M} \mathrm{PBS,} \mathrm{30 \%} \mathrm{eth-}$ ylene glycol, $20 \%$ glycerol) at $-20^{\circ} \mathrm{C}$ and used later for immunocytochemistry.

\section{Immunocytochemistry}

Midbrain sections were removed from $-20^{\circ} \mathrm{C}$ storage and washed in KPBS buffer 4 times for 15 min each, immersed in $0.6 \%$ hydrogen peroxide for $30 \mathrm{~min}$, washed in KPBS buffer 4 times for 15 min each and then incubated with the following blocking solutions: Vector normal goat serum (Vector Laboratories, Burlingame, Calif., USA) for $60 \mathrm{~min}$; 3\% BSA (Sigma, St. Louis, Mo., 
USA) for $60 \mathrm{~min}$; Vector avidin for $20 \mathrm{~min}$, and Vector biotin for $20 \mathrm{~min}$. Sections were then incubated for $48 \mathrm{~h}$ in primary antibody to UCN1 (U4757; Sigma) or CRF (gift of Wylie Vale; Salk Institute, La Jolla, Calif., USA). These antibodies have been extensively characterized and previously applied to primate brain [3739]. The UCN1 antibody was diluted $1 / 15,000$ in $0.6 \%$ normal goat serum, $0.02 \mathrm{M} \mathrm{KPBS}$ and $0.4 \%$ Triton. The CRF antibody was diluted $1 / 3,000$ in $0.1 \%$ human $\alpha$-globulin-KPBS. The sections were then rinsed in KPBS buffer 4 times for 15 min each, incubated in Vector biotylinated goat anti-rabbit serum for $60 \mathrm{~min}$, washed in KPBS buffer 4 times for 15 min each, incubated with Vector ABC reagent for $60 \mathrm{~min}$, washed in KPBS buffer 4 times for $15 \mathrm{~min}$ each, incubated with $0.05 \%$ diaminobenzidine (Dojindo Laboratories, Kumamoto, Japan) containing 3\% hydrogen peroxide for approximately $5 \mathrm{~min}$, and finally washed in KPBS buffer 4 times for $15 \mathrm{~min}$ each. The sections were mounted on Superfrost Plus slides (Fischer, Santa Clara, Calif., USA) and dried overnight under vacuum. Then, they were further dehydrated via a graded series of ethanols, xylene and Histoclear. Finally, they were mounted under glass with DPX.

\section{Stereological Analysis of Immunostaining}

Midbrain sections were anatomically matched between animals using anatomical reference points. A Marianas Stereology Workstation (Intelligent Imaging Innovations, Denver, Colo., USA) with Slidebook 4.2 (Olympus Imaging Systems, Center Valley, Pa., USA) was used for analysis. Four levels of the dorsal raphe nucleus were immunostained for CRF fibers. Three levels of the midbrain, rostral to the dorsal raphe nucleus, were immunostained for UCN1 fibers. A montage of the entire area containing CRF- or UCN1-positive fibers was built by the workstation. The area containing the CRF- or UCN1-positive fibers was defined and measured (pixels and square micrometer total area). Next, the image was segmented into positive and negative pixels by Slidebook 4.2 and was examined at high magnification to verify that only specific-immunostained signal concentrated in fibers was highlighted. The positive pixel area was obtained and computed as percent of the total area in pixels.

As previously described by May et al. [39], the UNC1-positive cell bodies were located adjacent to the Edinger-Westphal nucleus in the supraoculomotor area (SOA), which is rostral to the UCN1 fiber area and the raphe nucleus. The area to be analyzed was outlined and montage containing the SOA was obtained. The detectable UCN1-positive cells were marked by the observer and tallied by Slidebook 4.2. All cell counts refer to detectable neurons only. Cells were counted at 4 levels through the rostrocaudal extent of the SOA and the total number of UCN1-positive cells was obtained for each animal. The individual totals were averaged to obtain the group means. In addition, Slidebook 4.2 provides micrometer measures of the outlined area. The thickness of each section $(25 \mu \mathrm{m} \times 4$ sections $=100 \mu \mathrm{m})$ was used as the length of the examined SOA region. The average area of the region for each animal (square micrometers outlined by Slidebook 4.2) was multiplied by the length to obtain the volume of the examined region (cubic micrometers $/ 10^{9}=$ cubic millimeters). The total number of UCN1-immunoreactive neurons in each animal was divided by the volume of the area examined to obtain the number of UCN1 neurons per cubic millimeter for each animal. The individual animal numbers of UCN1 neurons per cubic millimeter were then averaged to obtain the group means.

CRF and UCN in Monkey Midbrain

\section{Statistical Analysis}

The Student $t$ test was applied for comparison of 2 groups. All data comparing 4 groups were subjected to two-way analysis of variance (ANOVA) followed by Bonferroni's post hoc pairwise comparison. The variance within the groups reflects the difference between animals. Statistical analyses were conducted using the Prism Statistical software 5.0 (GraphPad Software Inc., San Diego, Calif., USA). $\mathrm{p}<0.05$ was considered statistically significant.

\section{Results}

\section{CRF Fiber Staining}

Robust CRF fiber staining was observed in the dorsal raphe nucleus. CRF fiber staining in the dorsal raphe nucleus from a representative animal in each group is illustrated in figure 1 . The positively stained fibers were segmented and highlighted in blue. Perceptibly, there appears to be a decrease in CRF fiber density in the SS animal treated with S-citalopram (Cit) compared to the $\mathrm{SS}$ animal treated with $\mathrm{Pb}$. The quantification of the CRF fiber density in $\mathrm{Pb}$-treated animals at 4 levels of the dorsal raphe is shown in figure 2 . The data are parsed into rostral (levels 1 and 2) and caudal (levels 3 and 4) regions of the dorsal raphe nucleus for the $\mathrm{Pb}$-treated groups. There was a significant difference between $\mathrm{HSR}+\mathrm{Pb}$ and $\mathrm{SS}+\mathrm{Pb}$ groups in the caudal region of the dorsal raphe nucleus, with $\mathrm{SS}+\mathrm{Pb}$ animals exhibiting a significantly higher $\mathrm{CRF}$ fiber density compared to $\mathrm{HSR}+\mathrm{Pb}$ animals ( $\mathrm{p}=$ 0.0170). There was no difference between the Pb-treated groups in the rostral region of the dorsal raphe nucleus. Figure 3 illustrates the effect of S-citalopram on overall CRF fiber density across all 4 levels of the dorsal raphe nucleus. Two-way ANOVA indicated that there was a significant effect of treatment $(p=0.0496)$, but no effect of stress sensitivity $(\mathrm{p}=0.6755)$ and no interaction $(\mathrm{p}=$ 0.3027 ). There was a significant difference between the SS groups, with the SS+Cit group showing a significantly lower CRF fiber density compared to the $\mathrm{SS}+\mathrm{Pb}$ group (Bonferroni's post hoc: $\mathrm{p}<0.05$ ). The HSR groups demonstrated no difference in CRF fiber density. There was no difference in the total area examined between the groups.

\section{UCN1 Fiber Staining}

Sections of the midbrain that were rostral to the dorsal raphe nucleus and encompassing the caudal linear nucleus contained a UCN1 fiber plexus that was used for analysis. UCN1 fiber staining in this area from representative HSR and SS animals is illustrated in figure 4. The posi- 

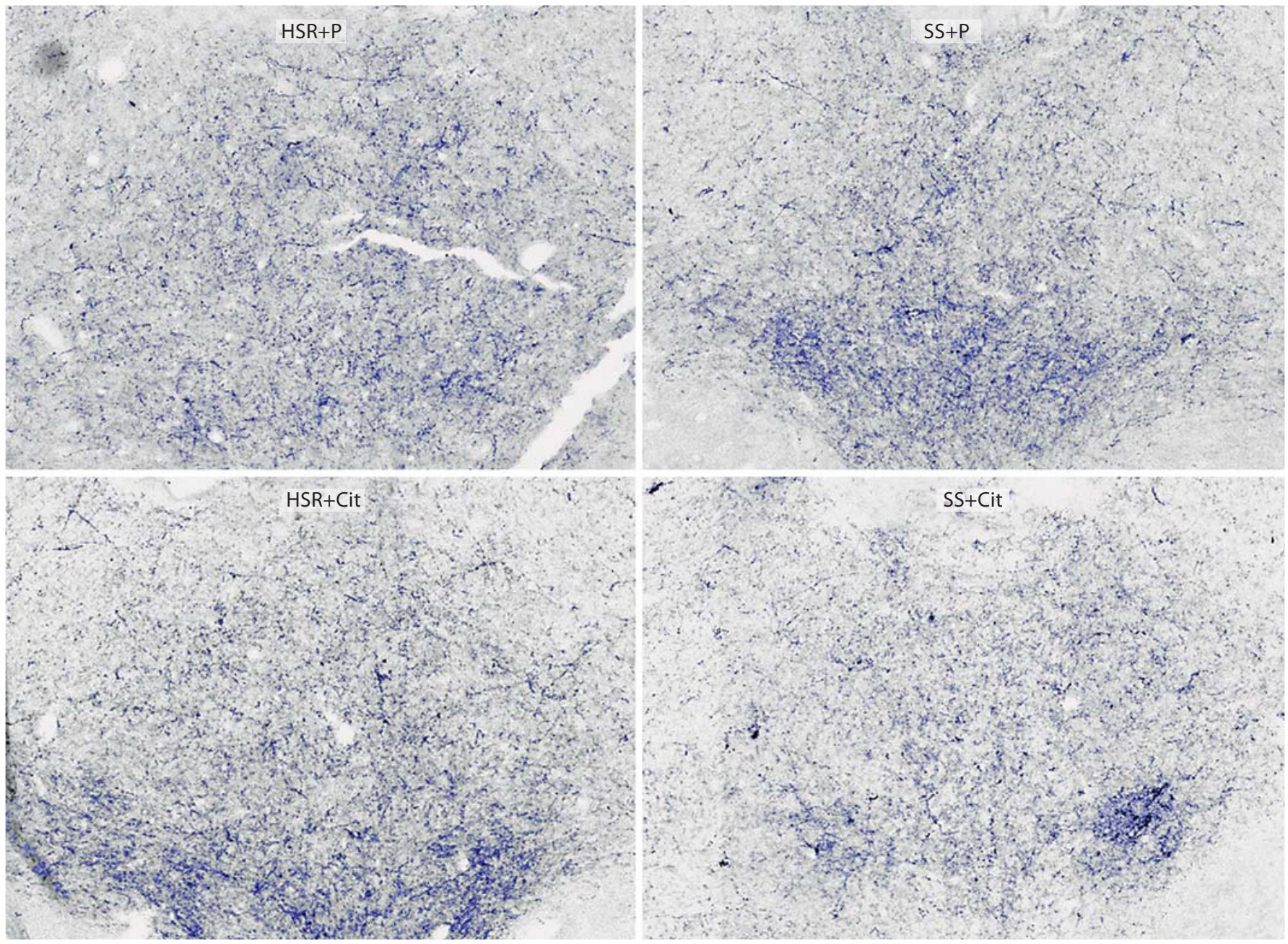

Fig. 1. Photomicrographs of CRF fiber staining in the dorsal raphe nucleus. Stereology montage of CRF fiber staining in the dorsal raphe nucleus in a representative animal from each treatment group. Sections were immunostained for CRF and segmented into

positively and negatively stained pixels. Blue: positive pixels. Cell bodies or debris were erased prior to pixel quantitation. Visually, there appears to be a lower density of CRF fibers in the SS+Cit animal. $\times 10$.

Fig. 2. CRF fiber density expressed as percent of total pixel area covered by CRFpositive fibers (pixels) in the $\mathrm{Pb}$-treated groups. Rostral and caudal regions of the dorsal raphe nucleus of the HSR and SS groups treated with placebo $(\mathrm{HSR}+\mathrm{Pb}$ and $\mathrm{SS}+\mathrm{Pb}$, respectively). In the rostral region, there was no significant difference between the groups. In caudal region, there was a significant difference (F test: $\mathrm{p}=$ 0.0170 ) between $\mathrm{HSR}+\mathrm{Pb}$ and $\mathrm{SS}+\mathrm{Pb}$ groups, with the $\mathrm{SS}+\mathrm{Pb}$ group exhibiting a significantly higher CRF fiber density compared to the $\mathrm{HSR}+\mathrm{Pb}$ group.

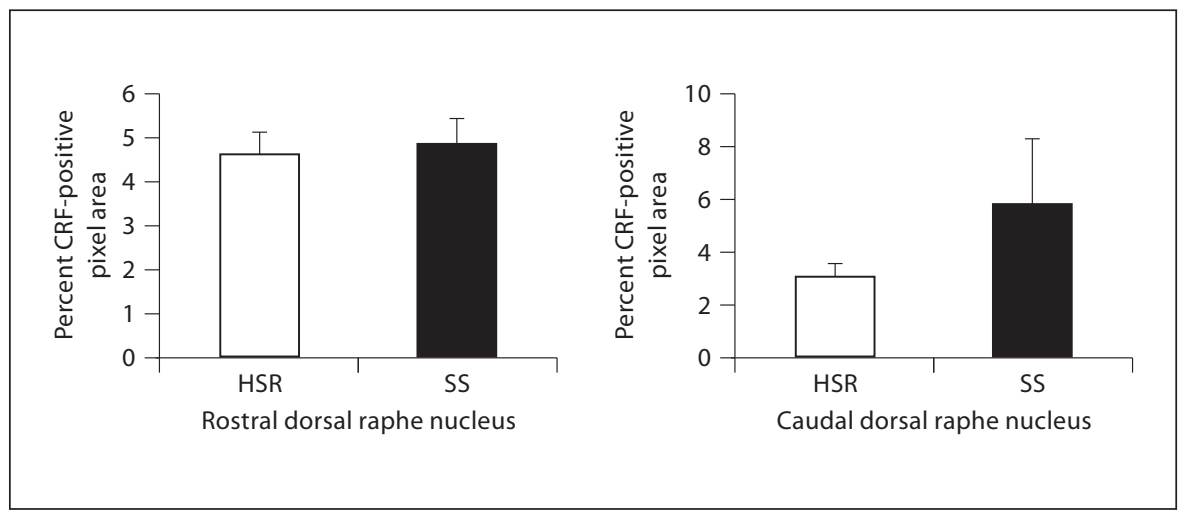




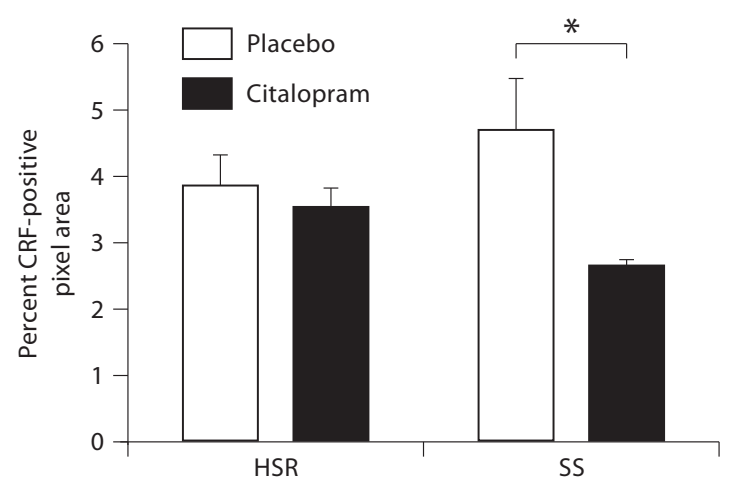

Fig. 3. Average CRF-positive pixels across 4 levels of the dorsal raphe nucleus in all groups expressed as percent of total area examined. There was a significant effect of treatment $(\mathrm{p}=0.0496)$, but no effect of stress sensitivity $(\mathrm{p}=0.6755)$ and no interaction $(\mathrm{p}=0.3027)$. The SS+Cit group exhibited a significantly lower CRF fiber density compared to the SS+Pb group. * Significant difference (Bonferroni: $\mathrm{p}<0.05$ ).

tively stained fibers were segmented and highlighted in blue. Any UCN1-positive neurons were eliminated before pixel counting. There appears to be a higher density of UCN1 fibers in the HSR animals compared to the SS animals. The quantification of the UCN1 fiber density across 3 levels of the midbrain is shown in figure 5. The average UCN1-positive pixel area as a percentage of the total area examined is shown. Two-way ANOVA indicated that there was a significant effect of stress sensitivity $(\mathrm{p}=0.047)$, but no effect of S-citalopram treatment ( $\mathrm{p}=$ $0.495)$ and no interaction $(\mathrm{p}=0.894)$. Thus, there was a significant difference between the HSR and SS groups, with the HSR groups showing a significantly higher UCN1 fiber density compared to the SS groups, but Scitalopram had no effect (fig. 5). The total examined area did not differ between the groups.

\section{UCN1 Cell Body Staining in SOA}

The location of UCN1 cell bodies differs between rodents and primates. In our cynomolgus macaques, UCN1 cell bodies were located adjacent to the Edinger-Westphal nucleus in the supraoculomotor area (SOA) of the rostral midbrain. Our observations agree with and follow the anatomical characterization of UCN1 cell bodies in macaques by May et al. [39]. Figure 6 illustrates UCN1 cell body staining in this area from a representative animal. The quantification of the UCN1 cell bodies across

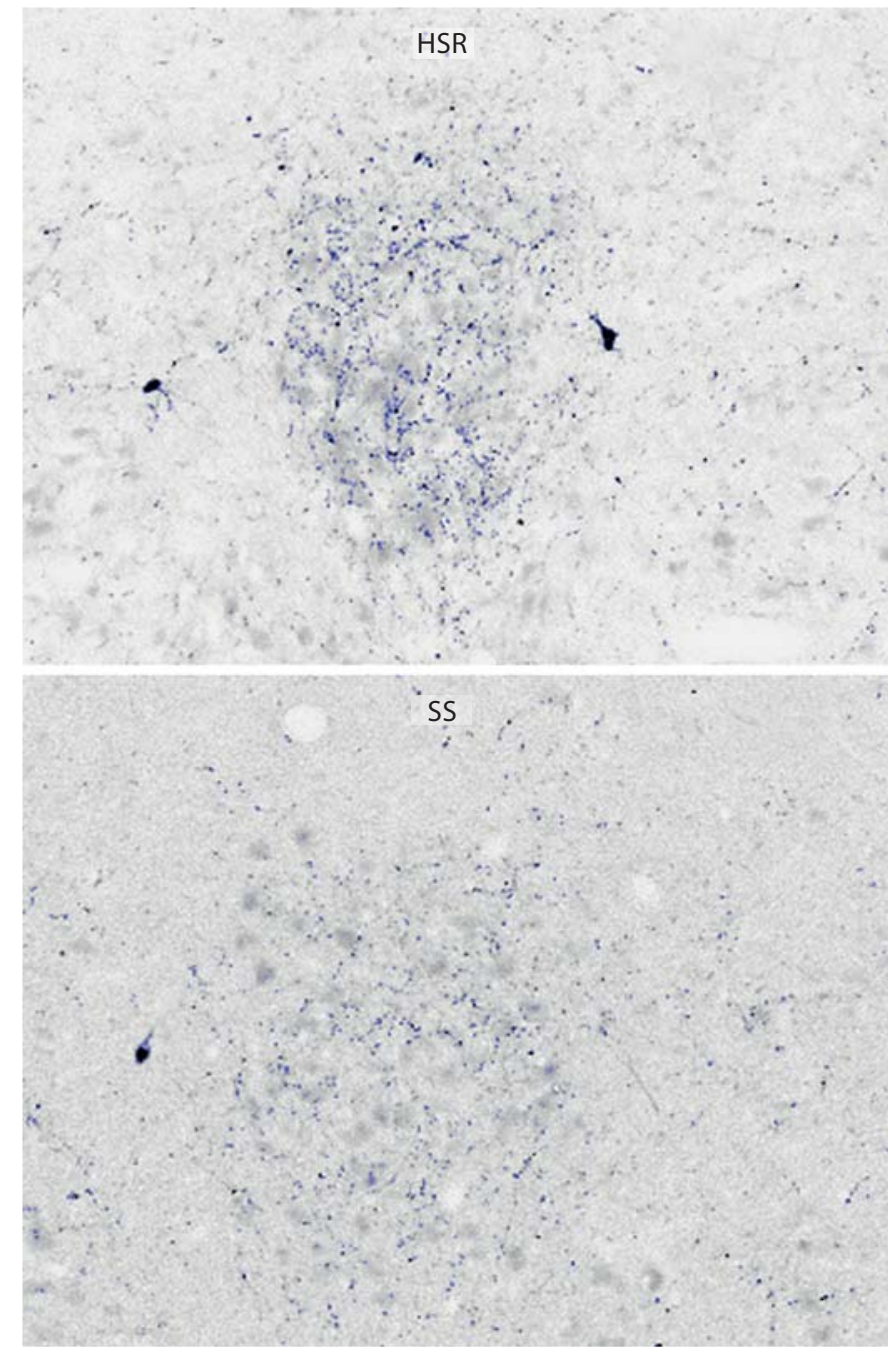

Fig. 4. Photomicrographs of UCN1-positive fibers in the midbrain, rostral to the dorsal raphe nucleus, in a representative HSR animal and an SS animal. Sections were immunostained for UCN1 and segmented into positively and negatively stained pixels. Blue: positive pixels. Cell bodies or debris were erased prior to pixel quantitation. Visually, there were few UCN1 fibers in the SS groups.

4 levels of the SOA is shown in figure 7. The number of neurons in the 4 levels was summed, generating the total number of neurons per animal. The average of the animal totals was then obtained for each group, and these data are shown in figure 7a. By two-way ANOVA, there was a significant effect of stress sensitivity $(p=0.04)$, but no effect of treatment $(\mathrm{p}=0.43)$. There was a nearly significant interaction ( $\mathrm{p}=0.056)$, supporting the suggestion that S-citalopram increased detectable UCN1 neu- 


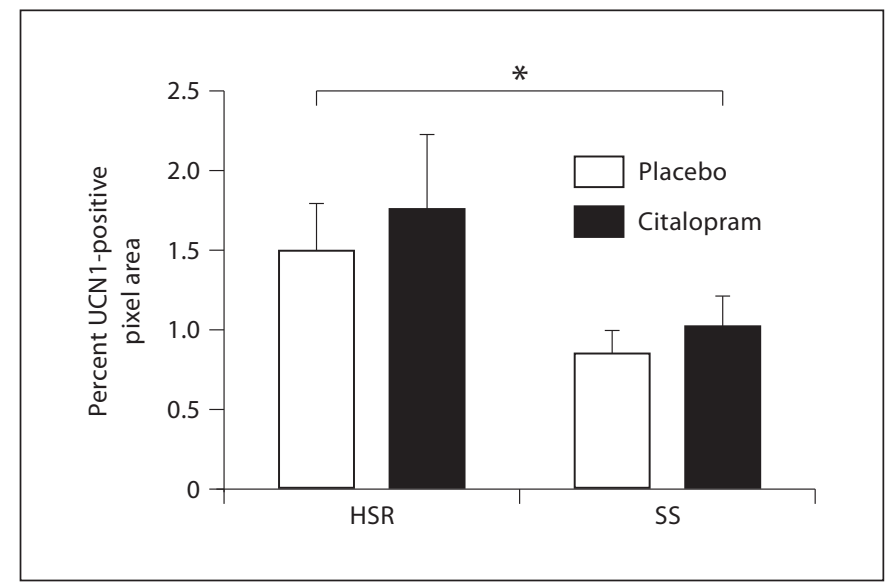

Fig. 5. Average UCN1-positive pixels across 3 levels of the rostral midbrain in all groups expressed as percent of total area examined. There was a significant effect of stress sensitivity $(\mathrm{p}=$ $0.0477)$, but no effect of S-citalopram treatment $(\mathrm{p}=0.4958)$ and no interaction $(\mathrm{p}=0.8946)$. The SS groups exhibited a significantly lower UCN1 fiber density compared to the HSR groups. * Significant difference (ANOVA: $\mathrm{p}<0.05$ ).

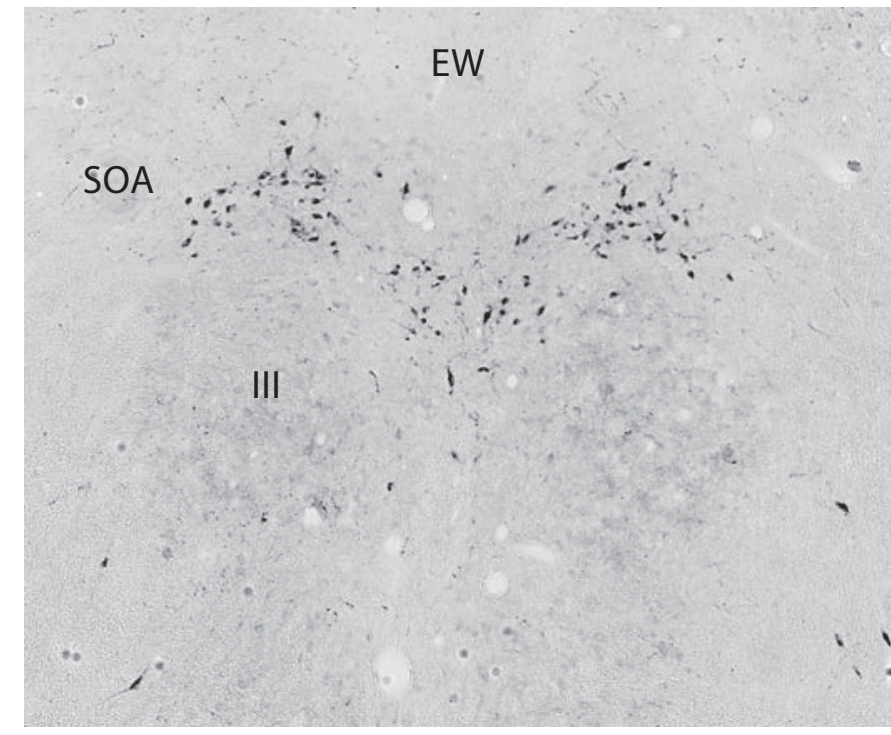

Fig. 6. Photomicrograph of UCN1-positive cells in the SOA near the Edinger-Westphal nucleus (EW) in a representative animal. The cells are superior to the oculomotor (third) nucleus (III).

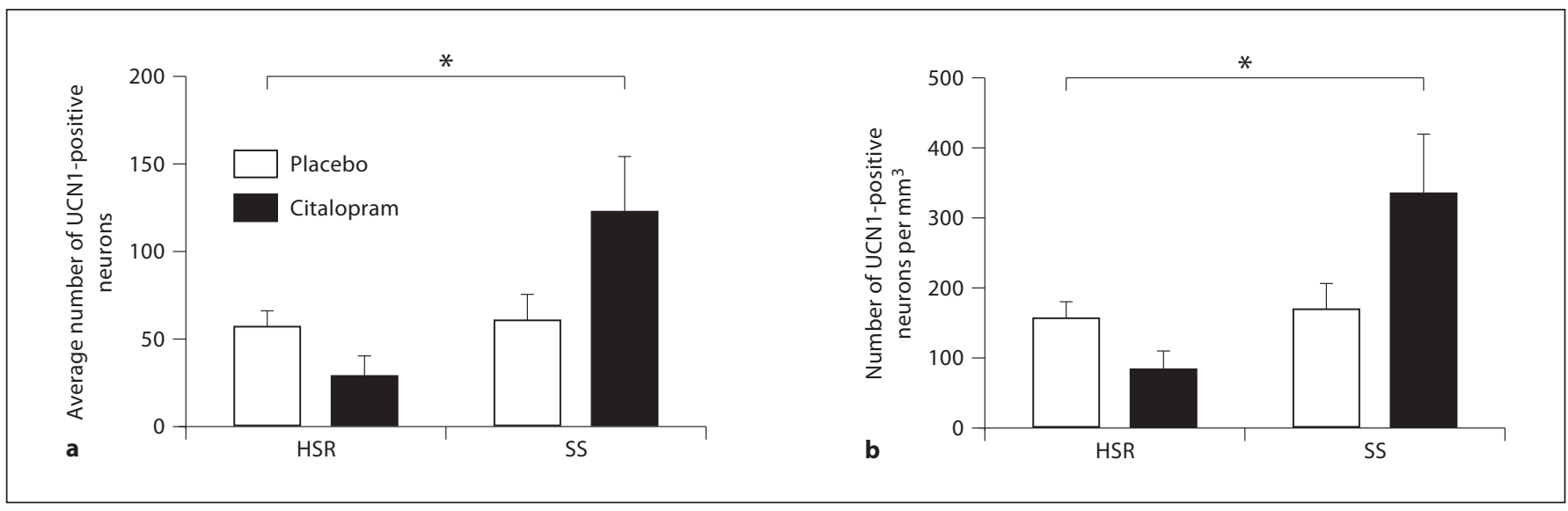

Fig. 7. Overall averages of UCN1-positive cells in the SOA. The number of neurons across 4 levels was summed, generating the total number of neurons per animal. Then, the average of the animal totals was obtained for each group. * Significant difference (ANOVA: $\mathrm{p}<0.05$ ). a Average number of UCN1-positive neurons. By two-way ANOVA, there was a significant effect of stress sensitivity $(p=0.04)$, but no effect of treatment $(p=0.43)$. There was a nearly significant interaction $(\mathrm{p}=0.056)$, indicating that $\mathrm{S}$-cital-

rons in the SS group, but not the HSR group. In figure $7 \mathrm{~b}$, the number of UCN1-positive neurons per cubic millimeter volume for each group is illustrated. By two-way ANOVA, there was a significant effect of stress sensitivity $(\mathrm{p}=0.04)$, but no effect of treatment $(\mathrm{p}=0.43)$. There opram increased detectable UCN1 neurons in the SS group, but not in the HSR group. b Average number of UCN1-positive neurons per cubic millimeter for each group. By two-way ANOVA, there was a significant effect of stress sensitivity $(\mathrm{p}=0.04)$, but no effect of treatment $(\mathrm{p}=0.43)$. There was a nearly significant interaction $(\mathrm{p}=0.056)$, indicating that $\mathrm{S}$-citalopram increased detectable UCN1 neurons in the SS group, but not in the HSR group.

was a nearly significant interaction $(\mathrm{p}=0.056)$, further supporting the suggestion that $\mathrm{S}$-citalopram increased the number of detectable UCN1 neurons in the SS group, but not in the HSR group. The volume examined did not differ between the groups. 


\section{Discussion}

The neurobiological basis of individual differences in stress sensitivity and the potential pharmacological remediation are important issues in obvious fields such as psychiatry and immunology. More recently, gynecologists have recognized that individual differences in stress sensitivity play a role in the pathology of infertility $[4,40]$. We have previously shown that monkeys who are sensitive to stress-induced amenorrhea exhibit significantly more CRF mRNA and CRF protein in the caudal region of the PVN, significantly more CRF mRNA in the thalamus and a significantly higher CRF fiber density in the central nucleus of the amygdala relative to stress-resilient animals under nonstressed basal conditions [13]. In contrast, rodent strains with different sensitivities to stress exhibit no difference in hypothalamic CRF expression [41].

In our model, stress induced reproductive dysfunction in sensitive individuals, but even in nonstressed conditions, SS monkeys have chronically lower ovarian steroid secretion. In a new cohort of animals, 15 weeks of S-citalopram treatment elevated estrogen and progesterone secretion in SS animals. Since S-citalopram is an SSRI, we have recently examined its effect on serotonin-related gene expression [9]. Although SS animals had a significantly lower expression of Fev, TPH2, SERT and 5-HT $1 \mathrm{~A}$ genes, S-citalopram had no effect. Nonetheless, the mechanism of action of S-citalopram on the serotonin system is well accepted. This led us to speculate that S-citalopram may elevate extracellular serotonin without affecting gene expression, and in turn, elevated extracellular serotonin may regulate other stress-related neural systems.

CRF-producing neurons and projections are widespread and play a role in stress-related psychiatric disorders [42]. CRF innervation of the serotonergic dorsal raphe nucleus has been described and CRF receptors are found in the dorsal raphe of rodents [23, 43, 44]. Moreover, CRF regulates serotonin release [28, 45-47].

Previous studies have also demonstrated that serotonin innervates CRF neurons in the hypothalamus [48, 49], and newer data indicate that serotonin decreases CRF [50, 51], perhaps via inhibitory interneurons [52]. Therefore, we hypothesized that S-citalopram increased extracellular serotonin, which decreased CRF production and delivery to extrahypothalamic regions including the dorsal raphe. This could further facilitate serotonin neurotransmission and further decrease CRF, thereby establishing a feed-forward loop. We also hypothesized that SS animals would exhibit a lower pro- duction and delivery of UCN1, and that S-citalopram would increase UCN1.

This study found that, indeed, the CRF fiber density in the caudal portion of the dorsal raphe nucleus was increased in SS individuals, and that administration of Scitalopram reduced the CRF fiber density only in the SS group. The CRF innervation of the dorsal raphe is believed to originate in the caudal portion of the PVN and in the amygdala, where we had previously observed an increase in CRF in SS individuals relative to SR individuals [13]. This difference was reflected in the CRF fiber density in the dorsal raphe of the Pb-treated animals. Extrapolating from the current data, it is likely that S-citalopram reduces CRF gene and protein expression in the PVN and amygdala. Although a similar effect has been observed in rodents with other antidepressants [50, 51], the mechanism of action has not been addressed. We speculate that SSRIs elevate serotonin in the synaptic cleft, which in turn decreases CRF production and neurotransmission. Further studies to look at CRF in the hypothalamus and thalamus from this same cohort of animals are planned.

A small, but fairly consistent UCN1 fiber plexus amenable to measurement was detected in an area between the Edinger-Westphal nucleus and the dorsal raphe nucleus near the serotonergic caudal linear nucleus. As predicted, the UCN1 fiber density was significantly higher in HSR than in SS animals. However, S-citalopram had no effect on UCN1 fiber density although this little plexus may not represent UCN1 fiber density in other regions. Norepinephrine and the locus ceruleus have also been implicated in stress- and CRF-related peptide interactions [53], and cholinergic neurons in the Edinger-Westphal nucleus are adjacent to UCN1 neurons as well [39]. Clearly, the afferent innervation of the midbrain UCN1 neurons needs to be defined.

UCN1 decreases feeding behavior and also participates in the stress response [54-56]. UCN1 binds to CRFR2 with greater affinity than CRF, suggesting that UCN1 preferentially binds to CRF-R2. Both UCN1 knockout mice and CRF-R2 knockout mice exhibit increased anxiety-like behavior [56]. Thus, it has been generalized that activation of CRF-R1 by CRF increases anxiety-like behavior, whereas activation of CRF-R2 by UCN1 decreases anxiety-like behavior. Our observations in HSR and SS animals are consistent with this generalization. SS animals have a higher CRF fiber density and lower UCN1 fiber density in the raphe region of the midbrain. In addition, we observed that SS animals exhibit more behavioral agitation, an indication of anxiety in primates (un- 
published), as measured by undirected activity in novel settings of a free play test and the Human Intruder test [57]. It is reasonable to hypothesize that in SS animals, the higher CRF and lower UCN1 innervations lead to a decrease in serotonin neurotransmission, which in turn contributes to their stress sensitivity.

In rodents, the main population of urocortin-positive cells has been described as lying within the EdingerWestphal nucleus of the midbrain. However, in primates, only a few urocortin cells are found within the confines of the Edinger-Westphal nucleus. The midbrain UCN1 cell bodies in macaques are located adjacent to the Edinger-Westphal nucleus, in an area referred to as the SOA [39]. These neurons also express cocaine and amphetamine regulated transcript or CART $[25,58]$. There were more detectable UCN1-positive neurons in the SS groups than in the HSR groups, which is the inverse of the fiber density. It is attractive to speculate that the transport of UCN1 may be compromised in SS animals (which we also observed with GnRH) although other mechanisms cannot be excluded. However, it is important to note that the two-way difference between HSR and SS groups was largely due to the increase in detectable UCN1 neurons in the SS group treated with S-citalopram (SS+Cit). This was supported by the nearly significant difference in interaction, which indicates that S-citalopram had an effect in the SS group, but not in the HSR group. Indeed, the number of UCN1-positive neurons was similar in the $\mathrm{HSR}+\mathrm{Pb}$, $\mathrm{HSR}+\mathrm{Cit}$ and $\mathrm{SS}+\mathrm{Pb}$ groups. The basal, constitutive expression of $\mathrm{UCN} 1$ is moderate across species, but restraint stress rapidly elevates UCN1 mRNA in rodents [56]. None of the monkeys were stressed at the time of euthanasia. Hence, the modest and similar expression of UCN1 in the cell body region of the $\mathrm{HSR}+\mathrm{Pb}, \mathrm{HSR}+\mathrm{Cit}$ and $\mathrm{SS}+\mathrm{Pb}$ groups may be a reflection of environmental normality. The increase in detectable UCN1-positive neurons in the SS+Cit animals is consistent with the increase in UNC1 mRNA observed in rodents treated with the antianxiety drug alprazolam [59] although its mechanism of action differs from that of S-citalopram.

As noted above, $S$-citalopram treatment also increased peak estradiol and progesterone secretion in SS monkeys. This study and previous work [9] have approached the neural systems acted upon by S-citalopram, which in turn are thought to impinge upon the GnRH system and ultimately determine ovarian steroid secretion. However, it is also valid to question whether the increase in estrogen and progesterone in SS animals could cause the observed changes in the CRF and UCN1 systems. We have unpublished data showing that ovarian steroids decrease
CRF and increase UCN1 fiber density in the raphe region, thus we cannot rule out this possibility. However, ovarian hormones alter gene expression in serotonin neurons [60], and citalopram did not [9]. Perhaps it is the combination of elevated extracellular serotonin and ovarian steroids that influences the CRF and UNC1 systems in SS animals in a positive-feedback fashion.

In summary, in regions of the midbrain that contain serotonin cell bodies there is a higher density of CRF fibers and a lower density of UCN1 fibers in SS macaques compared to HSR macaques. In addition, with 15 weeks of S-citalopram treatment, there was a decrease in CRF fiber density in the dorsal raphe and a trend toward increased UCN1 production in the cell body region of SS animals. There was no effect of citalopram on UCN1 fiber density. The decrease in CRF delivered to the dorsal raphe could allow serotonin to further increase, producing a feed-forward circuit in which CRF was further decreased. Together, these actions could reduce anxiety and sensitivity to stress.

\section{Acknowledgments}

This study was supported by the Eunice Kennedy Shriver National Institute of Child Health and Human Development via cooperative agreement U54 HD 18185 as part of the specialized Cooperative Centers Program in Reproduction and Infertility Research, NIH grant MH62677 to C.L.B., a predoctoral fellowship to K.V.W. from the NIH Fogarty International Center grant TW/ HD-00668 to P. Michael Conn, and NIH RR00163 for the operation of the Oregon National Primate Research Center.

References

$>_{1}$ Boivin J, Bunting L, Collins JA, Nygren KG: International estimates of infertility prevalence and treatment-seeking: potential need and demand for infertility medical care. Hum Reprod 2007;22:1506-1512.

2 Reindollar RH, Novak M, Tho SP, McDonough PG: Adult-onset amenorrhea: a study of 262 patients. Am J Obstet Gynecol 1986; 155:531-543.

-3 Berga SL, Loucks TL: Use of cognitive behavior therapy for functional hypothalamic amenorrhea. Ann NY Acad Sci 2006;1092: 114-129.

4 Marcus MD, Loucks TL, Berga SL: Psychological correlates of functional hypothalamic amenorrhea. Fertil Steril 2001;76:310-316.

$\checkmark 5$ Williams NI, Berga SL, Cameron JL: Synergism between psychosocial and metabolic stressors: impact on reproductive function in cynomolgus monkeys. Am J Physiol Endocrinol Metab 2007;293:E270-E276. 
-6 Bethea CL, Pau FK, Fox S, Hess DL, Berga SL, Cameron JL: Sensitivity to stress-induced reproductive dysfunction linked to activity of the serotonin system. Fertil Steril 2005;83: 148-155.

7 Bethea CL, Streicher JM, Mirkes SJ, Sanchez RL, Reddy AP, Cameron JL: Serotonin-related gene expression in female monkeys with individual sensitivity to stress. Neuroscience 2005;132:151-166.

8 Cameron JL: Reproductive dysfunction in primates, behaviorally induced; in Fink G (ed): Encyclopedia of Stress. New York, Academic Press, 2000, pp 366-372.

$\checkmark$ Lima FB, Centeno ML, Costa ME, Reddy AP, Cameron JL, Bethea CL: Stress-sensitive female macaques have decreased fifth Ewing variant (Fev) and serotonin-related gene expression that is not reversed by citalopram. Neuroscience 2009;164:676-691.

10 Bethea CL, Centeno ML, Cameron JL: Neurobiology of stress-induced reproductive dysfunction in female macaques. Mol Neurobiol 2008;38:199-230.

-11 Centeno ML, Sanchez RL, Cameron JL, Bethea CL: Hypothalamic expression of serotonin $1 \mathrm{~A}, 2 \mathrm{~A}$ and $2 \mathrm{C}$ receptors and GAD67 in female cynomolgus monkeys with different sensitivity to stress. Brain Research 2007; 1142:1-12.

-12 Centeno ML, Sanchez RL, Cameron JL, Bethea CL: Hypothalamic gonadotrophinreleasing hormone expression in female monkeys with different sensitivity to stress. J Neuroendocrinol 2007; 19:594-604.

13 Centeno ML, Sanchez RL, Reddy AP, Cameron JL, Bethea CL: Corticotropin-releasing hormone and pro-opiomelanocortin gene expression in female monkeys with differences in sensitivity to stress. Neuroendocrinology 2007;86:277-288.

- 14 Dobson H, Ghuman S, Prabhakar S, Smith R: A conceptual model of the influence of stress on female reproduction. Reproduction 2003; 125:151-163.

15 Wang R, Millam JR: Corticotropin-releasing-hormone-immunopositive nerve elements in apposition to chicken gonadotropin-releasing-hormone-I-containing perikarya in Japanese quail (Coturnix coturnix japonica) brain. Cell Tissue Res 1999;297: 223-228.

16 Williams CL, Nishihara M, Thalabard JC, Grosser PM, Hotchkiss J, Knobil E: Corticotropin-releasing factor and gonadotropinreleasing hormone pulse generator activity in the rhesus monkey: electrophysiological studies. Neuroendocrinology 1990;52:133137.

-17 Bao AM, Hestiantoro A, van Someren EJ, Swaab DF, Zhou JN: Colocalization of corticotropin-releasing hormone and oestrogen receptor- $\alpha$ in the paraventricular nucleus of the hypothalamus in mood disorders. Brain 2005;128:1301-1313.
Raadsheer FC, Hoogendijk WJ, Stam FC, Tilders FJ, Swaab DF: Increased numbers of corticotropin-releasing hormone expressing neurons in the hypothalamic paraventricular nucleus of depressed patients. Neuroendocrinology 1994;60:436-444.

19 Delville Y, Stires C, Ferris CF: Distribution of corticotropin-releasing hormone immunoreactivity in golden hamster brain. Brain Res Bull 1992;29:681-684.

20 Frim DM, Robinson BG, Pasieka KB, Majzoub JA: Differential regulation of corticotropin-releasing hormone mRNA in rat brain. Am J Physiol 1990;258:E686-E692.

21 Keegan CE, Herman JP, Karolyi IJ, O’Shea KS, Camper SA, Seasholtz AF: Differential expression of corticotropin-releasing hormone in developing mouse embryos and adult brain. Endocrinology 1994;134:25472555.

22 Vaughan J, Donaldson C, Bittencourt J, Perrin MH, Lewis K, Sutton S, Chan R, Turnbull AV, Lovejoy D, Rivier C, et al: Urocortin, a mammalian neuropeptide related to fish urotensin I and to corticotropin-releasing factor. Nature 1995;378:287-292.

23 Linthorst AC: Interactions between corticotropin-releasing hormone and serotonin: implications for the aetiology and treatment of anxiety disorders. Handb Exp Pharmacol 2005:181-204.

24 Vasconcelos LA, Donaldson C, Sita LV, Casatti CA, Lotfi CF, Wang L, Cadinouche MZ, Frigo L, Elias CF, Lovejoy DA, Bittencourt JC: Urocortin in the central nervous system of a primate (Cebus apella): sequencing, immunohistochemical, and hybridization histochemical characterization. J Comp Neurol 2003;463:157-175.

25 Kozicz T: Neurons colocalizing urocortin and cocaine-and-amphetamine-regulated transcript immunoreactivities are induced by acute lipopolysaccharide stress in the Edinger-Westphal nucleus in the rat. Neuroscience 2003;116:315-320.

26 Skelton KH, Owens MJ, Nemeroff CB: The neurobiology of urocortin. Regul Pept 2000; 93:85-92.

27 Ryabinin AE, Weitemier AZ: The urocortin 1 neurocircuit: ethanol sensitivity and potential involvement in alcohol consumption. Brain Res Rev 2006;52:368-380.

28 Clark MS, McDevitt RA, Hoplight BJ, Neumaier JF: Chronic low dose ovine corticotropin releasing factor or urocortin II into the rostral dorsal raphe alters exploratory behavior and serotonergic gene expression in specific subregions of the dorsal raphe. Neuroscience 2007;146:1888-1905.

29 Hammack SE, Pepin JL, DesMarteau JS, Watkins LR, Maier SF: Low doses of corticotropin-releasing hormone injected into the dorsal raphe nucleus block the behavioral consequences of uncontrollable stress. Behav Brain Res 2003;147:55-64.
0 Hammack SE, Schmid MJ, LoPresti ML, Der-Avakian A, Pellymounter MA, Foster AC, Watkins LR, Maier SF: Corticotropinreleasing hormone type 2 receptors in the dorsal raphe nucleus mediate the behavioral consequences of uncontrollable stress. J Neurosci 2003;23:1019-1025.

- 31 Pernar L, Curtis AL, Vale WW, Rivier JE, Valentino RJ: Selective activation of corticotropin-releasing factor-2 receptors on neurochemically identified neurons in the rat dorsal raphe nucleus reveals dual actions. J Neurosci 2004;24:1305-1311.

32 Cameron JL, Bytheway JA, Guay S, Bethea CL, Kerr DI, Rockcastle N, Perel JM, Axelson DA: Treatment with a serotonin reuptake inhibitor increases reproductive hormone secretion in stress-sensitive monkeys. Abstracts 34th Annual Meeting of the Society for Neuroscience, San Diego, 2004.

33 Rochat B, Amey M, Baumann P: Analysis of enantiomers of citalopram and its demethylated metabolites in plasma of depressive patients using chiral reverse-phase liquid chromatography. Ther Drug Monit 1995;17: 273-279.

- 34 Sit DK, Perel JM, Helsel JC, Wisner KL: Changes in antidepressant metabolism and dosing across pregnancy and early postpartum. J Clin Psychiatry 2008;69:652-658.

35 Berod A, Hartman BK, Pujol JF: Importance of fixation in immunohistochemistry: use of formaldehyde solutions at variable $\mathrm{pH}$ for the localization of tyrosine hydroxylase. J Histochem Cytochem 1981;29:844-850.

36 Simmons DM, Arriza JL, Swanson LW: A complete protocol for in situ hybridization of messenger RNAs in brain and other tissues with radio-labeled single-stranded RNA probes. J Histotechnol 1989;12:169-181.

37 Palkovits M, Brownstein MJ, Vale W: Distribution of corticotropin-releasing factor in rat brain. Fed Proc 1985;44:215-219.

38 Foote SL, Cha CI: Distribution of corticotropin-releasing-factor-like immunoreactivity in brainstem of two monkey species (Saimiri sciureus and Macaca fascicularis): an immunohistochemical study. J Comp Neurol 1988; 276:239-264.

39 May PJ, Reiner AJ, Ryabinin AE: Comparison of the distributions of urocortin-containing and cholinergic neurons in the perioculomotor midbrain of the cat and macaque. J Comp Neurol 2008;507:1300-1316.

40 Giles DE, Berga SL: Cognitive and psychiatric correlates of functional hypothalamic amenorrhea: a controlled comparison. Fertil Steril 1993;60:486-492.

-41 Gomez F, Lahmame A, de Kloet ER, Armario A: Hypothalamic-pituitary-adrenal response to chronic stress in five inbred rat strains: differential responses are mainly located at the adrenocortical level. Neuroendocrinology 1996;63:327-337. 
42 Clark MS, Kaiyala KJ: Role of corticotropinreleasing factor family peptides and receptors in stress-related psychiatric disorders. Semin Clin Neuropsychiatry 2003;8:119136.

43 Lowry CA, Rodda JE, Lightman SL, Ingram $\mathrm{CD}$ : Corticotropin-releasing factor increases in vitro firing rates of serotonergic neurons in the rat dorsal raphe nucleus: evidence for activation of a topographically organized mesolimbocortical serotonergic system. J Neurosci 2000;20:7728-7736.

44 Valentino RJ, Lucki I, van Bockstaele E: Corticotropin-releasing factor in the dorsal raphe nucleus: linking stress coping and addiction. Brain Res 2010;1314:29-37.

-45 Forster GL, Pringle RB, Mouw NJ, Vuong SM, Watt MJ, Burke AR, Lowry CA, Summers $\mathrm{CH}$, Renner KJ: Corticotropin-releasing factor in the dorsal raphe nucleus increases medial prefrontal cortical serotonin via type 2 receptors and median raphe nucleus activity. Eur J Neurosci 2008;28:299-310.

- 46 Summers CH, Kampshoff JL, Ronan PJ Lowry CA, Prestbo AA, Korzan WJ, Renner KJ: Monoaminergic activity in subregions of raphe nuclei elicited by prior stress and the neuropeptide corticotropin-releasing factor. J Neuroendocrinol 2003;15:1122-1133.

-47 Thomas E, Pernar L, Lucki I, Valentino RJ: Corticotropin-releasing factor in the dorsal raphe nucleus regulates activity of lateral septal neurons. Brain Res 2003;960:201-208.
48 Saphier D, Welch JE, Farrar GE, Nguyen NQ, Aguado F, Thaller TR, Knight DS: Interactions between serotonin, thyrotropin-releasing hormone, and substance $\mathrm{P}$ in the CNS regulation of adrenocortical secretion. Psychoneuroendocrinology 1994;19:779-797.

49 Phelix CF, Liposits Z, Paull WK: Serotonin$\mathrm{CRF}$ interaction in the bed nucleus of the stria terminalis: a light microscopic doublelabel immunocytochemical analysis. Brain Res Bull 1992;28:943-948.

50 Lowry CA, Hale MW, Plant A, Windle RJ, Shanks N, Wood SA, Ingram CD, Renner KJ, Lightman SL, Summers CH: Fluoxetine inhibits corticotropin-releasing factor (CRF)induced behavioural responses in rats. Stress 2009;12:225-239.

51 Stout SC, Owens MJ, Nemeroff CB: Regulation of corticotropin-releasing factor neuronal systems and hypothalamic-pituitary-adrenal axis activity by stress and chronic antidepressant treatment. J Pharmacol Exp Ther 2002;300:1085-1092.

52 Bethea CL, Centeno ML: Ovarian steroid treatment decreases corticotropin-releasing hormone (CRH) mRNA and protein in the hypothalamic paraventricular nucleus of ovariectomized monkeys. Neuropsychopharmacology 2008;33:546-556.
3 Koob GF: Corticotropin-releasing factor, norepinephrine, and stress. Biol Psychiatry 1999;46:1167-1180.

54 Spina M, Merlo-Pich E, Chan RK, Basso AM, Rivier J, Vale W, Koob GF: Appetite-suppressing effects of urocortin, a CRF-related neuropeptide. Science 1996;273:1561-1564.

55 Oki Y, Sasano H: Localization and physiological roles of urocortin. Peptides 2004;25: 1745-1749.

56 Pan W, Kastin AJ: Urocortin and the brain. Prog Neurobiol 2008;84:148-156.

57 Bethea CL, Streicher JM, Coleman K, Pau FK, Moessner R, Cameron JL: Anxious behavior and fenfluramine-induced prolactin secretion in young rhesus macaques with different alleles of the serotonin reuptake transporter polymorphism (5HTTLPR). Behav Genet 2004;34:295-307.

58 Lima FB, Henderson JA, Reddy AP, Tokuyama Y, Hubert GW, Kuhar MJ, Bethea CL: Unique responses of midbrain CART neurons in macaques to ovarian steroids. Brain Res 2008;1227:76-88.

59 Skelton KH, Nemeroff CB, Knight DL, Owens MJ: Chronic administration of the triazolobenzodiazepine alprazolam produces opposite effects on corticotropin-releasing factor and urocortin neuronal systems. J Neurosci 2000;20:1240-1248.

-60 Bethea CL, Lu NZ, Gundlah C, Streicher JM: Diverse actions of ovarian steroids in the serotonin neural system. Front Neuroendocrinol 2002;23:41-100. 